UNIVERSITY of NORTH FLORIDA.

\section{Journal of Counseling Sexology \& Sexual} Wellness: Research, Practice, and Education

\title{
Deconstructing Sexual Shame: Implications for Clinical Counselors and Counselor Educators
}

Stacey Diane A. Litam

Cleveland State University

Megan Speciale

Palo Alto University

Follow this and additional works at: https://digitalcommons.unf.edu/jcssw

Part of the Counseling Commons

\section{Recommended Citation}

Litam, S. A., \& Speciale, M. (2021). Deconstructing Sexual Shame: Implications for Clinical Counselors and Counselor Educators. Journal of Counseling Sexology \& Sexual Wellness: Research, Practice, and Education, 3 (1), 14-24. https://doi.org/10.34296/03011045

This Article is brought to you for free and open access by the Brooks College of Health at UNF Digital Commons. It has been accepted for inclusion in Journal of Counseling Sexology \& Sexual Wellness: Research, Practice, and Education by an authorized administrator of UNF Digital Commons. For more information, please contact Digital Projects.

(C) 2021 All Rights Reserved 


\title{
Deconstructing Sexual Shame: Implications for Clinical Counselors and Counselor Educators
}

\author{
Stacey D.A. Litam \\ Cleveland State University
}

\author{
Megan Speciale \\ Palo Alto University
}

\begin{abstract}
Although clients often seek treatment for sexuality-related concerns, counselors may lack the competence, comfort, and skills to adequately address these issues. Counselors may address these treatment barriers by developing a sex-affirming counseling framework. The following article outlines the importance of deconstructing sexual shame within clinical counseling settings and provides specific strategies to enhance the sexual empowerment of clients.
\end{abstract}

Keywords: sexuality, intimacy, shame, counseling, sex affirming

\section{Introduction}

Over the last decade, topics related to sex and sexuality have experienced a resurgence. As counselors began to shift their focus away from the medical model, a new, holistic, sex-positive worldview emerged. The medicalization of sex therapy was replaced with a more salutogenic view of sexual health. The dominant model for sex-positive counseling focuses on achieving or maintaining sexual health (C. Murray, Pope, \& Willis, 2017; Southern \& Cade, 2011). Because sexual health is intimately linked to wellness across the lifespan (Flynn et al., 2016), the ways in which topics related to sex and sexuality contribute to mental health disorders are of paramount importance within the counseling profession. Although topics related to sex, sexuality, and intimacy represent important areas of foci within clinical and research areas, many mental health professionals lack basic competence and comfort to address sexuality issues (Harris \& Hays, 2008; Russell, 2012) due to the complexity of these topics and lack of training in counselor education programs (Authors, 2019, 2020; Russell, 2012).

The construct of sexual health represents more than the relative absence of symptoms and considers opportunities to obtain sexual fulfillment (Southern \& Cade, 2011). According to the World Health Organization (2002), sexuality represents a central aspect of being human and encompasses sex, gender identity and roles, sexual identity, eroticism, pleasure, intimacy, and reproduction (para. 7). While clients often seek counseling to address sexuality-related concerns (C. Murray et al., 2017; Southern \& Cade, 2011), many counselors struggle to address these issues in ways that produce meaningful change (C. Murray et al., 2017). Given the expansive definition of sexual health in combination with the apparent need to increase counselor competency in this area, counselors are called to develop a sex-affirming counseling framework and learn strategies to address sexuality concerns successfully within the therapeutic setting. The authors de- fine a sex-affirming counseling framework as a therapeutic relationship characterized by unconditional acceptance and celebration of salutogenic human sexuality wherein clients are empowered to achieve a worldview about sex, sexuality, and intimacy without the presence of sexual shame. The following article identifies contributing factors to the development of sexual shame including the influence of religious messages, social messages, and sexual trauma. Next, the importance for deconstructing sexual shame in counseling is described. Specific strategies to help counselors develop a sex-affirming framework and common issues related to sexual shame are provided. The article concludes with ethical considerations as they relate to referring clients to specialists and feelings of countertransference.

\section{Sexual Shame}

Sexual shame is a specific form of shame caused by negative evaluations of one's sexual identity, behaviors, attractions, thoughts, or feelings (Gordon, 2017). Sexual shame is related to one's past sexual experiences and behaviors (Pulverman \& Meston, 2020), and often encompasses topics related to sex and sexuality, sexual desires, and deeply personal aspects of sexual identity that are not changeable, such as attraction and gender. The need to understand sex-

\begin{tabular}{|c|}
\hline Corresponding Author \\
\hline Stacey Diane A. Litam \\
Cleveland State University \\
2121 Euclid Ave \\
Julka Hall Office 284 \\
Cleveland, OH 44115 \\
E: s.litam@csuohio.edu \\
P: (216)523-7148 \\
\hline
\end{tabular}


ual shame better has been clearly established in the literature (Levison, 2012; Shadbolt, 2009). Although past studies have sought to quantify sexual shame by correlating global shame experiences with measures of sexual attitudes, behaviors, and beliefs (Kroll et al., 2007; K. M. Murray, Ciarrocchi, \& Murray-Swank, 2007), these efforts overlooked the experiences of people who functioned well overall but who experienced sexual shame with regard to sexual experiences or sexual identity (Billard, 2018). Psychometrically sound measures that assess shame are additionally limited (Rizvi, 2009), and a clear need continues to exist for measures that provide clinical utility and accurately assess sexual shame across genders (Gordon, 2017; Kyle, 2013).

\section{Factors That Influence Sexual Shame}

Religious Messages. The extant body of research indicates religious or theologically conservative individuals who view pornography and engage in non-marital lust and masturbation may experience profound guilt from violating moral codes and expectations (Grubbs, Exline, Pargament, Hook, \& Carlisle, 2014; Grubbs \& Hook, 2016; Thomas, Alper, \& Gleason, 2017). When religious ideologies emphasize how sex acts should only occur within the institution of marriage, individuals' abilities to explore their sexual identities, engage in sexual behaviors, or seek information about contraception, abortion, and safer sex practices may be limited. The marked incongruence between internalized religious values with one's own experiences of sexual desire may contribute to feelings of guilt, shame, and internal conflict (Grubbs et al., 2014; Grubbs \& Hook, 2016). Indeed, individuals from conservative religious backgrounds appear to be at higher risk for developing relational distress and experiencing sexual shame compared to their non-religious counterparts (Leonhardt, Willoughby, \& Young-Petersen, 2017; Perry, 2015).

Religious messages endorsing a patriarchal worldview that undervalues the role of women while prioritizing the male contribution are embedded within Roman religious ideologies (i.e., Judaism and Christianity; Holland, 2012) and exist across diverse religious traditions. Religious and cultural messages about sex, sexuality, and sexual health may additionally carry undertones that convey moral judgment and gender-based assumptions which counter sex-positive approaches (Bay-Cheng, 2003; Manning, 2014; Rubinsky \& Cooke-Jackson, 2016, 2017). Scholars have identified disparaging messages about the inferiority of women compared to men across Muslim (Huassain, 2017), Buddhist (Paudel \& Dong, 2017), and Hindu (Franiuk \& Shain, 2011) teachings. Religious messages additionally venerate the values of chastity, purity, and abstinence (Cooke-Jackson, Orbe, Johnson, \& Kauffman, 2014) while advocating for the desexualization of women's bodies (Huassain, 2017). These religious-based messages about sex and sexuality may ad- ditionally lead to feelings of sexual shame as evidenced by the fact that the majority of sacred texts promote abstinence (Cooke-Jackson et al., 2015), position sex as dirty and dangerous (Rubinsky \& Cooke-Jackson, 2016, 2017), contain oppressive gender stereotypes (Heisler, 2014), perpetuate rape myths (Franiuk \& Shain, 2011), and avoid directly addressing issues related to sexual health and intimacy (Holman \& Kellas, 2018).

Rigid teachings about sexual identity also permeate religious messages. Strict adherence to heterosexual identities and monogamous partnerships exist in Muslim law (Huassain, 2017) and are notoriously grounded in the Bible (Moses, 2020). Clobber passages, traditionally marginalizing scriptures used out of context to condemn same sex activity (Miner, 2002; Moses, 2020), may create additional disparaging messages that promote the presence of sexual shame. Christian dogma conceptualizes same-sex behavior as diseased, perverse, sinful, and inferior (Barton, 2010). Consequently, lesbian, gay, bisexual, transgender, and queer (LGBTQ) individuals may experience conflict as they negotiate disparate religious and sexual identities. These challenges may be especially marked for religious LGBTQ people of color, particularly those who reside along the Bible Belt in the United States (see Litam et al., 2020)—a geographical region associated with religion and encompassing northern Texas to western North Carolina and stretching from Mississippi to Kentucky (Brunn, Webster, \& Archer, 2011). Existing research has linked feelings of shame, guilt, inadequacy, trauma, and suicidality in LGBTQ persons who lack affirming religious messages (Hattie \& Beagan, 2013; Sherry, Adelman, Whilde, \& Quick, 2010). Lesbian, gay, and bisexual individuals may also experience rejection from their religious communities and family members (Barrow \& Kuvalanka, 2011; Dahl \& Galliher, 2012; Hattie \& Beagan, 2013), which increases the likelihood of developing mental health symptoms and rates of homelessness.

Social Messages. From an early age, children begin receiving messages about reproduction, their bodies, and sexual health. These internalized messages about sex, sexuality, and bodies may influence the development of sexual shame. Early messages girls receive about sexual health and reproduction have lasting impressions on identity development, conceptualization of sexual activity, and relationships with their bodies across the lifespan (Rubinsky \& Cooke-Jackson, 2016, 2017). Children who are punished or ridiculed for engaging in sexually curious behaviors often experience feelings of guilt and shame (Southern \& Cade, 2011). The taboo nature of topics related to sex and sexuality often perpetuates the internalization of sexual shame. Girls and women who have internalized the prohibited nature of sexual topics may be more likely to keep the details of their sexual abuse hidden (Carnes, 2002; Morrison \& Ferris, 2002), which only serves to maintain and perpetuate feelings of sexual shame. Indeed, 
early messages from families of origin may lead to the stifling of natural sexual expression, exploration, and curiosity, and result in ongoing experiences of sexual shame.

Women uniquely face contradicting societal messages at the intersection of ageism and sexual desire. On one hand, media perpetuates endless messages that attribute women's societal value to their sexual currency. Thus, women who are perceived as young, attractive, and within child-bearing years are given more power. The presence of sexual currency is juxtaposed against another societal message that vilifies women who demonstrate overt sexuality, on the other hand. Women may be marginalized through slut shaming, the double standard which stigmatizes the sexuality of women but praises the character of men who engage in the same types of overt sexuality (Ringrose \& Harvey, 2015). Although women are negatively affected by childhood lessons and ongoing media messages, the harmful societal messages which contribute to the presence of sexual shame are not limited to gender.

Boys and men are subjected to societal messages that communicate conflicting notions about the nature of sex, intimacy, and sexual expression. For example, boys and men exposed to societal messages that center cisheteronormativity may endorse attitudes that value sexual performance and aggression, rather than demonstrating vulnerability, communicating feelings, or enhancing intimacy (Southern \& Cade, 2011). Boys and men may additionally become subjected to shaming messages when they are perceived by others as embodying traits perceived as feminine, such as expressing emotions, endorsing fairness and equity, and engaging in help-seeking behaviors. Following experiences of male sexual victimization, endorsement of heteronormative scrips and toxic cultural messages about masculinity may perpetuate the presence of sexual shame in boys and men (Hlavka, 2016). The experiences of sexual shame in men appear to be distinct from women and may include specific aspects related to sexual inexperience distress, masturbation/pornography remorse, libido disdain, body dissatisfaction, dystonic sexualactualization, and sexual performance insecurity (Gordon, 2017). Counselors are therefore encouraged to adhere to a feminist, strength-based, and sex-affirming counseling approach that enables boys and men with sexual shame to reframe harmful patriarchal narratives surrounding masculinity.

Technology has ushered in a new wave of sexual social messaging and provides novel opportunities for facilitating sexual health education. Increasing numbers of children, teens, and adults are looking to the Internet and social media as an informal source of sexuality education (Mitchell, Ybarra, Korchmaros, \& Kosciw, 2013). Several websites, mobile applications, and forms of game-based learning have emerged to improve the sexual health education of adolescents (Haruna et al., 2018), which may help to address es- sential knowledge gaps young people may experience in the absence of formal comprehensive sex education. For example, the gamification of sexual health education may be more motivating for adolescents compared to traditional teaching methods (Chu et al., 2015; Kashibuchi \& Sakamoto, 2001), and can promote safer sexual behaviors through storytelling, role-plays, and avatars (Haruna et al., 2018). However, while there are benefits associated with the increased accessibility of sexuality information online, there are also increased opportunities for the spread of sexual misinformation. Individuals who access sexually explicit online content may be exposed to unrealistic and potentially harmful portrayals of sex, gender roles, objectification, sexual communication, and consent that may be internalized and contribute toward the development of sexual shame. While pornography and erotica may be useful tools in achieving sexual satisfaction and exploring erotic desire, there is a clear need for increased pornography literacy among viewers in light of growing evidence that the messages inherent in mainstream pornography can shape viewers' attitudes and expectations about sex, intimacy, and relationships in problematic ways (Owens, Behun, Manning, \& Reid, 2012). Porn literacy can be cultivated through curriculum and sex-positive conversations that empower viewers to interpret sexually explicit media while learning to identify and challenge their own pre-existing notions, beliefs, and values about sex, bodies, and intimacy.

Sexual Trauma. Extant literature has linked the development of sexual shame to experiences of sexual trauma. Women who have survived child sexual abuse (CSA) report higher levels of sexual shame and experience greater difficulty recovering from psychological and sexual dysfunctions (Feiring, Taska, \& Chen, 2002; Feiring, Taska, \& Lewis, 2002; Pulverman, Kilimnik, \& Meston, 2018). Involvement with forced or coerced sexual acts deemed wrong and dirty by society may contribute to the internalization of feelings of sexual shame (Feiring, Taska, \& Lewis, 2002). For survivors of sexual trauma, shame may be associated with feelings of powerlessness, inadequacy, self-condemnation, disgrace, humiliation/embarrassment, or feeling damaged (Weiss, 2010). In a study conducted by Vidal and Petrak (2007), 75\% of female survivors of sexual assault reported feelings of shame following the traumatic event. Moreover, a study of adult women with histories of childhood sexual abuse (CSA; N $=120$ ) indicated the role of sexual shame completely mediated the relationship between CSA and sexual function (Pulverman \& Meston, 2020). Based on these findings, counselors must be knowledgeable about strategies to deconstruct sexual shame to promote wellbeing and improve sexual function in clients with CSA histories.

Lack of Sex Education. Several factors exist that may influence a disparity of sex education for children and teens. Many educators and teachers lack the awareness, knowledge, and skills needed to confidently address topics related to sex, 
sexuality, intimacy, and bodies. Sexual shame may be inadvertently communicated through messages from parents and educators who experience discomfort when addressing these topics. Indeed, the adults responsible for discussing topics related to sex and sexuality often report barriers in doing so. Feelings of discomfort, communication issues, and lack of knowledge on topics related to sex education result in avoidance of sex related discussions in parents and educators (Jerman \& Constantine, 2010). As a result, young people are left unable to develop a deeper understanding about sex and intimacy. These topics remain taboo, and young people may internalize incorrect beliefs related to reproductive and sexual health as something shameful that should be kept a secret (Rubinsky \& Cooke-Jackson, 2017).

When sex education does occur within educational settings, topics are often addressed in problematic ways. Although research has clearly illuminated how safer sex practices reduce occurrences of unplanned pregnancies and rates of sexually transmitted infections, sexual education programs most often disseminate abstinence-only education or abstinence until marriage education (Malone \& Rodriguez, 2011; Santelli et al., 2017). It is also common for sex and health education in $\mathrm{K}-12$ settings to be segregated by gender, which prevents teens from accessing information about other genders, and reinforces the mystification of sex and health issues of the opposite sex (Luker, 2006). This segregation may also contribute to harmful gender identity-related microaggressions and decreased access to knowledge for transgender, non-binary, and intersex students who may be inappropriately placed into single-sex classrooms. Additionally, the overt and covert messages that silence topics related to intimate health often minimize young girls' need for intimacy and pleasure (Gunning, Cooke-Jackson, \& Rubinsky, 2019).

\section{Deconstructing Sexual Shame in Counseling}

Sexual shame is pervasive across cultures and communities, and throughout the lifespan. Thus, counselors must be prepared to encounter clients who are experiencing mental, emotional, and sexual health issues related to, and impacted by, clients' feelings of shame. While sexual healthcare has historically been viewed as beyond professional counselors' scope of practice, scholars in the mental health field have urged the integration of sexual wellness discussion throughout the counseling process, regardless of presenting issue or concern (Buehler, 2017; Southern \& Cade, 2011). As evidenced by a professional identity rooted in wellness, human development, and social justice, professional counselors are uniquely positioned to address sexual health concerns within the context of clients' holistic wellbeing.

\section{Developing a Sex-Affirming Counseling Framework}

The primary tool in addressing sexual shame with clients is the counselor's ability to embody a sex-affirming stance within the therapeutic relationship. Notably, affirming beliefs about sexuality may not come naturally to counselors due to their own personal histories of sexual shame. Consequently, it becomes imperative for all mental health professionals first to examine their own beliefs, values, and biases about sexuality critically and consider how these attitudes may impact their ability to approach sexuality from a positive, empowering perspective (Wilson, 2019). Scholars have demonstrated how sexual beliefs that are rigid, rooted in conservative religious ideologies, and discriminatory in nature (e.g., sexist, heterosexist, transphobic) can be deleterious to affirming therapeutic relationships (Author, 2019; Bidell, 2014; McGeorge, Carlson, \& Toomey, 2013). Thus, it is vital that counselors seek out opportunities to increase their sexuality knowledge and self-awareness through continued sexuality education, sexuality-focused supervision, peer consultation, and personal counseling (Author, 2020; Russell, 2012; Wilson, 2019).

A sex-affirming framework of counseling centers on the assertion that sex is a natural part of the human experience and offers important contributions to clients' mental and emotional wellbeing, relational health, and overall life satisfaction. Counselors can exemplify a sex-affirming stance with clients by normalizing the topic of sexual discussion with congruence and comfort. Sexuality is also viewed as expansive, emergent, and pluralistic - that is, counselors acknowledge that sexuality is experienced in innumerable ways that are shaped by the client's unique social, cultural, and environmental contexts. Although values related to consent, equality, and responsibility are emphasized, sex-affirming counselors also recognize that there is no one "right" kind of sexuality and that all individuals create their own meanings related to sexual morality. In other words, sex-affirming counselors regard all sexual behaviors occurring between informed and consenting partners as potentially healthy and beneficial forms of intimacy.

A sex-affirming approach to counseling is also responsive to multicultural diversity and intersectionality. Clients that possess marginalized identities (e.g., LGBTQ+ individuals, people of Color, people with disabilities, people from impoverished backgrounds) often face increased sexual health risks, such as decreased access to sexual healthcare and increased sexual stigmatization (WHO, 2011). As such, counselors must recognize how discrimination systems such as white supremacy, patriarchy, and cisheteronormativity inform societal values about sexuality, as well as how discriminatory sexual norms may impact clients' sexual wellness. As each client possesses multiple identities that contribute to their unique position of privilege and oppression, counselors should explore the sexual health implications of their clients' intersectional lived experiences. 


\section{Common Issues Related to Sexual Shame}

Counselors are called to explore the existence of sexual shame and its impact on the client's presenting issues even when clients present into counseling for non-sexual reasons. The existing body of research has illuminated the negative effects of sexual shame on wellness (Feiring, Taska, \& Chen, 2002; Feiring, Taska, \& Lewis, 2002; Pulverman \& Meston, 2020) and the intimate relationship between sexual health and wellness across the lifespan (Flynn et al., 2016). Sexual shame has a broad range of implications for clients' overall health and may have negative associated outcomes for psychological, sexual, and relational functioning.

Internalized sexual shame may be a contributing factor to symptoms of depression and anxiety (Tangney \& Dearing, 2002; Willie et al., 2016). Impairments related to sexual shame may also include difficulties with sexual desire and arousal, increased genito-pelvic pain, difficulty achieving orgasm, and may also lead to out-of-control sexual behaviors (Braun-Harvey \& Vigorito, 2016; Pulverman \& Meston, 2020). According to findings from Pulverman and colleagues (2018), approximately 65 to $85 \%$ of women who present with sexual dysfunction have experienced CSA. Additionally, individuals with high levels of sexual shame may experience challenges related to intimacy within their sexual and romantic relationships, which may contribute to asymmetrical desire, increased conflict, and resentment between partners (Sellers, 2017).

The insidious effects of shame on gender and sexual minority (GSM) persons are especially marked. Internalized homophobia and concealment have been linked to higher rates of shame (Show \& Cheng, 2010; Sherry et al., 2010). Indeed, GSM persons who experience shame about their affectional and/or gender identities may struggle with embracing aspects of their authentic selves in ways that disconnect them from partners, peers, and GSM community members (Mereish \& Poteat, 2015), and contribute to poor quality of relationships (Liang et al., 2002). Counselors are therefore encouraged to assess for the presence of sexual shame with all clients, regardless of presenting concern.

\section{Addressing Sexual Shame in Therapeutic Settings}

Because sexuality is considered taboo by many cultures, clients are often denied the experience of openly and honestly discussing sexual health within social networks, which may contribute to feelings of reluctance and discomfort in initiating sexual discussion in therapy. A client entering into counseling for the first time may not feel like sexuality is appropriate or relevant to their reasons for seeking counseling, so the counselor is responsible for conveying that sex and intimacy are significant facets of overall health and wellness (Sellers, 2017). The PLISSIT model (Permission, Limited Information, Specific Suggestions, and Intensive Therapy;
Annon, 1976) details the importance of giving clients explicit permission to discuss sexuality in counseling, which can begin as early as the informed consent and continue throughout the counseling relationship. Clients facing sexual shame can benefit from the assurance and normalization provided by a trusted professional that their sexual concerns are a valid and meaningful aspect of their lives.

Upon normalizing sexual discussion and establishing rapport with clients, counselors may gain more information related to the client's current level of sexual health through formal and informal assessment. In addition to basic intake questions related to sexual and affectional identity, gender identity, and partnership status, the counselor may also include open-ended questions related to sexual wellness, such as: 1) How would you describe your current level of sexual or intimacy satisfaction? 2) What barriers do you face in experiencing healthy and pleasurable sexual intimacy? 3) What changes might you like to see is this area?

Because clients may come from religious or cultural backgrounds that discourage the open discussion of sex, counselors should strive to develop a strong therapeutic rapport and may convey sensitivity by framing questions as voluntary and directly related to the client's mental health. If the client indicates some distress related to sexual wellness, the counselor may explore the issue in more depth by incorporating questions geared to assess the role of culture and religion, family upbringing, relationship history, and previous sexual trauma in the client's sexual health concerns. From this discussion, the counselor acquires a more illustrative conceptualization of the impact of sexual shame on the client's presenting concerns. An additional structured assessment such as The Kyle Inventory of Sexual Shame (KISS; Kyle, 2013) may be useful in tracking changes in perceptions of sexual shame throughout the course of therapy.

While most clients can experience positive therapeutic outcomes by simply being accepted as sexual beings, some clients may require additional therapeutic interventions to recover from sexual shame (Annon, 1976). Counselors may provide clients additional information related to the presenting sexual issue, such as resources related to healing from religious sexual shame (Sellers, 2017) or sexual abuse (Maltz, 2012). This may also include providing clients with medically accurate information about their bodies, safer sex practices, variations in sexual activities, or other aspects related to intimacy enhancement. Many clients may experience relief from sexual shame by accessing increased information about sexuality, which can address the knowledge gaps incurred from prior sex education deficits and sexual stigmatization.

\section{Specific Strategies to Enhance Sexual Empowerment}

While permission-giving and psychoeducation are essential elements to addressing sexual shame, clients may also benefit from therapeutic interventions that further encourage 
the development of sexual empowerment. Given that sexual shame is primarily developed through the internalization of sex-negative messages, it can be especially helpful for clients to analyze their sexual shame narratives critically as they work toward envisioning a narrative of sexual empowerment. Interventions geared toward externalizing shame, exploring pleasure and desire, increasing body acceptance, and inspiring sexual creativity are essential in the journey to heal from sexual shame.

Narrative Interventions. Due to its focus on the externalization of problems and re-storying distressing narratives, narrative therapy may be a particularly useful approach for deconstructing sexual shame. Sellers's (2017) framework of healing from religious sexual shame captures key narrative therapy concepts by working with the client to: 1) confront sexual misconceptions and stereotypes with accurate sexual health knowledge (i.e., "framing" the session); 2) embrace positive elements of sex and intimacy through claiming and celebrating meaningful sexual pleasure; 3) address feelings of secrecy and shame by sharing personal sexual narratives with the counselor and other compassionate support members; and 4) envision future goals related to sexual empowerment by considering the question, "What story do you want to write that will honor the beautiful, unique gift that is the sensual, powerful you?" (italics in orginal; Sellers, 2017, p. 111). Inviting clients to externalize their personal stories related to sexual shame empowers them to explore and deconstruct the hidden ideologies that have contributed to their sexual wellbeing and self-determine which beliefs and values are congruent with their current sexual worldview. Many clients are unaware how much of the baggage they carry with respect to sexuality are based on ideas in which they no longer agree. Identifying and illuminating these conflicts allows clients to propose sexual worldviews that are reflective of their enhanced understanding of sexuality, cultural and religious values, and future sexual wellness ambitions.

Somatic Interventions. Clients who have formed negative associations related to sex may report feeling disconnected or out-of-touch with their bodies, genitals, or other erogenous areas-body- and/or genital-shame, and sexual self-consciousness (Sanchez \& Kiefer, 2007). As defined by Hartley (2004), somatic therapy is a "holistic approach to therapy and healing that embraces body, mind, and spirit within a changing social, cultural, and spiritual context" and provides a useful supplement to traditional talk therapy by inviting clients to explore the embodiment of their cognitive meanings about sex (p. 1). Examples of somatic therapy include breathing, meditation, dance/movement-based interventions, and other body-based exercises that may assist clients to integrate newfound sexual knowledge within the body, allowing for deeper exploration of the barriers that clients may experience around accessing pleasure, desire, and empowerment. An example of this is the "Mirror Ac- ceptance" exercise, wherein clients are invited to explore and affirm the uniqueness of their bodies in the privacy of their own home. Once in a safe and private location, the client is encouraged to position a mirror that allows for them to gaze upon their unclothed body while offering positive affirmations such as "I accept myself, in this moment, just as I am" with mindful intent. This somatic intervention may also include observance of one's genitals, with more specific affirmations about the smell, taste, and appearance of the client's breasts, vulva, anus, penis, or testes. Clients are encouraged to develop their own personal affirming mantras in counseling to use as an anchor when negative thoughts are encountered during the exercise. It is important that counselors prepare their clients to address any feelings of discomfort, guilt, shame, and disgust that may arise during the exercise beforehand, including permission to discontinue the exercise when it no longer feels therapeutic. Somatic homework assignments including sensual self-touch, masturbation, and partnered intimacy (e.g., sensate focus) may also be used to generate self-acceptance with pleasure, desire, and eroticism.

Expressive Arts. An essential component to deconstructing sexual shame involves the client's "practice of possibilities," or the process of generating unique, novel, and emergent sexual meanings that serve to empower the client's sexual wellbeing (Author, 2018, p. 169). Because negative messaging about sex can be deeply engrained in the client's sexual self-schema, interventions involving creativity and self-expression may be particularly useful in enabling clients to re-imagine personal sexual meanings. Expressive interventions provide the client a non-verbal pathway to explore topics related to sex, allowing a process of "working through, clarifying, organizing, and expressing what is often felt and unnamed or named in ways that reduce the fullness of the experience" (Metzl, 2016, p. 6). Sexual shame and empowerment may be explored through paint, sculpture, collage, photography, music, and numerous other mediums. One example is the "Nourishing Pleasure" exercise, which is intended for established counseling relationships where the client has already been working on sexual shame-related issues. The exercise involves the client sketching or painting a portrait of their body, while imagining their body in the midst of joyful pleasure. During the sketch, the client reflects on the following questions: 1) How does pleasure nourish you? 2) Where do you feel it most profoundly? 3) What messages empower your joy? Your pleasure? Your sensuality? Through this exercise, the client can express and affirm their right to feel joyful pleasure, as well as document the empowering messages that enable their experience of joyful pleasure. The exercise may also be used to cultivate body acceptance, self-compassion, and increased awareness of sexual and erotic desires.

Group Interventions. Shame, by nature, is an emotion of isolation. Several researchers have suggested that "speak- 
ing shame," or sharing one's shame experiences with others, is a pivotal aspect of shame recovery (Brown, 2006; Kyle, 2013; Sellers, 2017). Group counseling and peersupport group models have shown to be effective in reducing shame and increasing shame resiliency in diverse populations (Gilbert \& Proctor, 2006; Milliken, 2008) and may be particularly suited to address the needs of clients experiencing sexual shame. Core processes involved in the group treatment of sexual shame include: 1) normalization of the existence of sexual shame, 2) mutual empathy development, 3 ) consciousness-raising about sociocultural norms related to sex, 4) peer support and guidance, and 5) cultivating empowerment through relational closeness (Kyle, 2013).

\section{Referral to Specialists}

Engaging in ethical sexuality counseling requires counselors to reflect on their scope of practice and areas of expertise to recognize when clients may require referral to other specialists. Whereas sexuality counseling addresses developmental influences on individual and relational sexual functioning (Southern \& Cade, 2011), sex therapy reflects a more specialized form of treatment that utilizes known technical interventions to treat sexual dysfunction (Althof, 2010). Additionally, if a client's sexual concern is related to a medical issue (e.g., weakened pelvic floor after childbirth, erection difficulties related to prostate cancer treatment), consultation and referral to a medical specialist may be advised. Thus, it is important that counselors build a referral network that includes sex therapists, gynecologists/urologists that specialize in sexual health, physical therapists that specialize in pelvic health, sex educators, and sexual product specialists and/or retailers.

Counselors must also acknowledge the treatment and ethical implications that may arise when referring clients to specialists. Specifically, counselors must carefully consider whether referral to a specialist is in the best interest of the client or due to their own feelings of personal discomfort (Binik \& Meana, 2009). Counselors are additionally encouraged to engage in open, honest conversations with their clients when topics related to sex and sexuality venture into areas of which the counselor has limited competence or training (Corley \& Schneider, 2002). Indeed, counselors are called to reflect on their professional scope of practice and refer clients to specialists, when applicable, to avoid doing harm (ACA; 2014).

\section{Attending to Countertransference}

Counselors may face countertransference during sexuality counseling as the result of their own sexual experiences or internalized feelings of sexual shame. Clients who explore intimate topics related to sexual, affectional, and gender identities, sexual activities, and experiences of sexual trauma may elicit feelings of countertransference in counselors. Counselors who experience countertransference in response to clients are encouraged to pursue supervision, process their feelings with colleagues, or engage in their own counseling to obtain valuable insight as to the reasons for their reactions (Fisher, 2004; Rodgers, 2011). Experiencing countertransference, including sexual feelings towards clients, may be normalized and in and of themselves, do not constitute sexual misconduct (Fisher, 2004).

\section{Conclusion}

As counselors continue to move away from the disease model of pathology, sexual health topics such as the implications of sexual shame on wellness must be conceptualized from a sex-affirming, holistic, and biopsychosocial perspective. The present article outlined the various factors and experiences that may contribute to feelings of sexual shame. To support clients, counselors may employ specific strategies to enhance sexual empowerment, including narrative interventions, somatic exercises, expressive arts, and group interventions. When countertransference occurs as clients explore issues related to sex, sexuality, and intimacy, counselors are encouraged to seek supervision, process their experiences, and pursue their own counseling to obtain insight. Finally, counselors must reflect on their areas of competence and consider referring clients to specialists when appropriate.

\section{References}

Althof, S. E. (2010). What's new in sex therapy (CME). The Journal of Sexual Medicine, 7(1), 5-13. doi:10.1111/j.1743-6109.2009.01433.x

American Counseling Association. (2014). Code of ethics. Author.

Annon, J. S. (1976). The PLISSIT model: A proposed conceptual scheme for the behavioral treatment of sexual problems. Journal of Sex Education and Therapy, 2(1), 1-15. doi:10.1080/01614576.1976.11074483

Barrow, K. M., \& Kuvalanka, K. A. (2011). To be jewish and lesbian: An exploration of religion, sexual identity, and familial relationships. Journal of GLBT Family Studies, 7(5), 470-492. doi:10.1080/1550428x.2011.623980

Barton, B. (2010). "Abomination"-life as a bible belt gay. Journal of Homosexuality, 57(4), 465-484. doi:10.1080/00918361003608558

Bay-Cheng, L. Y. (2003). The trouble of teen sex: The construction of adolescent sexuality through schoolbased sexuality education. Sex Education, 3(1), 6174. doi:10.1080/1468181032000052162

Bidell, M. P. (2014). Personal and professional discord: Examining religious conservatism and lesbian-, gay-, and bisexual-affirmative counselor competence. Jour- 
nal of Counseling $\mathcal{E}$ Development, 92(2), 170-179. doi:10.1002/j.1556-6676.2014.00145.x

Billard, T. J. (2018). (no) shame in the game: The influence of pornography viewing on attitudes toward transgender people. Communication Research Reports, 36(1), 45-56. doi:10.1080/08824096.2018.1549539

Braun-Harvey, D., \& Vigorito, M. (2016). Treating out of control sexual behavior : rethinking sex addiction. New York: Springer Publishing Company, LLC.

Brown, B. (2006). Shame resilience theory: A grounded theory study on women and shame. Families in Society: The Journal of Contemporary Social Services, 87(1), 43-52. doi:10.1606/1044-3894.3483

Brunn, S. D., Webster, G. R., \& Archer, J. C. (2011). The bible belt in a changing south: Shrinking, relocating, and multiple buckles. Southeastern Geographer, 51(4), 513-549.

Buehler, S. (2017). What every mental health professional needs to know about sex. New York, NY: Springer Publishing Company, LLC.

Carnes, P. (2002). Clinical management of sex addiction. New York: Brunner-Routledge.

Chu, S. K. W., Kwan, A. C., Reynolds, R., Mellecker, R. R., Tam, F., Lee, G., ... Leung, C. Y. (2015). Promoting sex education among teenagers through an interactive game: Reasons for success and implications. Games for Health Journal, 4(3), 168-174. doi:10.1089/g4h.2014.0059

Cooke-Jackson, A., Orbe, M. P., Johnson, A. L., \& Kauffman, L. (2014). Abstinence memorable message narratives: A new exploratory research study into young adult sexual narratives. Health Communication, 30(12), 1201-1212. doi:10.1080/10410236.2014.924045

Corley, M. D., \& Schneider, J. P. (2002). Disclosing secrets: Guidelines for therapists working with sex addicts and co-addicts. Sexual Addiction $\mathcal{E}$ Compulsivity, 9(1), 43-67. doi:10.1080/107201602317346638

Dahl, A., \& Galliher, R. V. (2012). The interplay of sexual and religious identity development in LGBTQ adolescents and young adults: A qualitative inquiry. Identity, 12(3), 217-246. doi:10.1080/15283488.2012.691255

Feiring, C., Taska, L., \& Chen, K. (2002). Trying to understand why horrible things happen: Attribution, shame, and symptom development following sexual abuse. Child Maltreatment, 7(1), 25-39. doi:10.1177/1077559502007001003

Feiring, C., Taska, L., \& Lewis, M. (2002). Adjustment following sexual abuse discovery: The role of shame and attributional style. Developmental Psychology, 38(1), 79-92. doi:10.1037/0012-1649.38.1.79

Flynn, K. E., Lin, L., Bruner, D. W., Cyranowski, J. M.,
Hahn, E. A., Jeffery, D. D., .. Weinfurt, K. P. (2016). Sexual satisfaction and the importance of sexual health to quality of life throughout the life course of u.s. adults. The Journal of Sexual Medicine, 13(11), 16421650. doi:10.1016/j.jsxm.2016.08.011

Franiuk, R., \& Shain, E. A. (2011). Beyond christianity: The status of women and rape myths. Sex Roles, 65(11-12), 783-791. doi:10.1007/s11199-011-9974-8

Gordon, A. M. (2017). How men experience sexual shame: The development and validation of the male sexual shame scale. The Journal of Men's Studies, 26(1), 105-123. doi:10.1177/1060826517728303

Grubbs, J. B., Exline, J. J., Pargament, K. I., Hook, J. N., \& Carlisle, R. D. (2014). Transgression as addiction: Religiosity and moral disapproval as predictors of perceived addiction to pornography. Archives of Sexual Behavior, 44(1), 125-136. doi:10.1007/s10508-0130257-Z

Grubbs, J. B., \& Hook, J. N. (2016). Religion, spirituality, and sexual addiction: A critical evaluation of converging fields. Sexual Addiction $\mathcal{E}$ Compulsivity, 23(2-3), 155-166. doi:10.1080/10720162.2016.1150925

Gunning, J. N., Cooke-Jackson, A., \& Rubinsky, V. (2019). Negotiating shame, silence, abstinence, and period sex: Women's shift from harmful memorable messages about reproductive and sexual health. American Journal of Sexuality Education, 15(1), 111-137. doi:10.1080/15546128.2019.1669511

Harris, S. M., \& Hays, K. W. (2008). Family therapist comfort with and willingness to discuss client sexuality. Journal of Marital and Family Therapy, 34(2), 239250. doi:10.1111/j.1752-0606.2008.00066.x

Hartley, L. (2004). Somatic psychology : body, mind and meaning. London Philadelphia: Whurr Publishers.

Haruna, H., Hu, X., Chu, S., Mellecker, R., Gabriel, G., \& Ndekao, P. (2018). Improving sexual health education programs for adolescent students through gamebased learning and gamification. International Journal of Environmental Research and Public Health, 15(9), 2027. doi:10.3390/ijerph15092027

Hattie, B., \& Beagan, B. L. (2013). Reconfiguring spirituality and sexual/gender identity: "It's a feeling of connection to something bigger, it's part of a wholeness.". Journal of Religion E Spirituality in Social Work: Social Thought, 32(3), 244-268. doi:10.1080/15426432.2013.801733

Heisler, J. M. (2014). They need to sow their wild oats. Emerging Adulthood, 2(4), 280-293. doi:10.1177/2167696814550196

Hlavka, H. R. (2016). Speaking of stigma and the silence of shame. Men and Masculinities, 20(4), 482-505. doi:10.1177/1097184x16652656

Holland, L. (2012). Women and roman religion. In E. James 
\& S. Dillon (Eds.), A companion to women in the ancient world (p. 204-214). Hoboken, NJ: Blackwell Publishing.

Holman, A., \& Kellas, J. K. (2018). "say something instead of nothing": Adolescents' perceptions of memorable conversations about sex-related topics with their parents. Communication Monographs, 85(3), 357-379. doi: $10.1080 / 03637751.2018 .1426870$

Huassain, S. (2017). Gender and sexuality in islam: An interface of patriarchy, religion and customary practices. Asian Journal of Humanities and Social Studies, 5(5). Retrieved from https://Www.ajouronline . com/index . php/AJHSS/article/view/4972

Jerman, P., \& Constantine, N. A. (2010). Demographic and psychological predictors of parent-adolescent communication about sex: A representative statewide analysis. Journal of Youth and Adolescence, 39(10), 11641174. doi:10.1007/s10964-010-9546-1

Kashibuchi, M., \& Sakamoto, A. (2001). The educational effectiveness of a simulation/game in sex education. Simulation $\mathcal{E}$ Gaming, 32(3), 331-343. doi:10.1177/104687810103200304

Kroll, J., Egan, E., Keshen, R., Carre, G., Johnson, M., \& Carey, K. (2007). Moral worry and religiosity in US and canadian college samples. Mental Health, Religion $\mathcal{F}$ Culture, 10(6), 621-630. doi:10.1080/13674670601064932

Kyle, S. (2013). Identification and treatment of sexual shame: Development of a measurement tool and group therapy protocol (Doctoral dissertation, American Academy of Clinical Sexologists). Retrieved from http: //www . esextherapy.com/dissertations/ Sarah\%20E\%20Kyle\%20Identification\%20and\% 20Treatment\%20of\%20Sexual\%20Shame\% 20Development\%20of\%20a\%20Measurement\% 20Tool\%20and\%20Group\%20Therapy\%20Protocol .$p d f$

Leonhardt, N. D., Willoughby, B. J., \& Young-Petersen, B. (2017). Damaged goods: Perception of pornography addiction as a mediator between religiosity and relationship anxiety surrounding pornography use. The Journal of Sex Research, 55(3), 357-368. doi:10.1080/00224499.2017.1295013

Levison, P. (2012). Sex, gender, and christianity. Eugene, Or: Cascade Books.

Liang, B., Tracy, A., Taylor, C. A., Williams, L. M., Jordan, J. V., \& Miller, J. B. (2002). The relational health indices: A study of women's relationships. Psychology of Women Quarterly, 26(1), 25-35. doi:10.1111/1471-6402.00040

Litam, S., Ford, D., Friday, A., Walker, B., Sutherlin, T., \& Band, M. (2020). Understanding the historical context of traditionally marginalizing biblical passages: Help- ing LGBTQ clients navigate the intersection of religion and sexual identity. In K. Strunk \& R. Feiszli (Eds.), Queering the deep south: Research on queer studies and LGBTQ lives in the southeast (p. 73-91). Charlotte, NC: Information Age Publishing.

Luker, K. (2006). When sex goes to school: Warring views on sex-and sex education-since the sixties. New York: W.W. Norton \& Co.

Malone, P., \& Rodriguez, M. (2011). Comprehensive sex education vs. abstinence-only-until- marriage programs. American Bar Association. Retrieved from https://www.americanbar.org/ groups/crsj/publications/human_rights _magazine_home/human_rights_vol38_2011/ human_rights_spring2011/comprehensive _sex_education_vs_abstinence_only_until _marriage_programs/

Maltz, W. (2012). The sexual healing journey: A guide for survivors of sexual abuse. New York, NY: William Morrow.

Manning, J. (2014). Paradoxes of (im)purity: Affirming heteronormativity and queering heterosexuality in family discourses of purity pledges. Women's Studies in Communication, 38(1), 99-117. doi:10.1080/07491409.2014.954687

McGeorge, C. R., Carlson, T. S., \& Toomey, R. B. (2013). An exploration of family therapists' beliefs about the ethics of conversion therapy: The influence of negative beliefs and clinical competence with lesbian, gay, and bisexual clients. Journal of Marital and Family Therapy, 41(1), 42-56. doi:10.1111/jmft.12040

Mereish, E. H., \& Poteat, V. P. (2015). A relational model of sexual minority mental and physical health: The negative effects of shame on relationships, loneliness, and health. Journal of Counseling Psychology, 62(3), 425437. doi:10.1037/cou0000088

Metzl, E. (2016). When art therapy meets sex therapy : creative explorations of sex, gender, and relationships. New York, NY: Routledge.

Milliken, R. (2008). Intervening in the cycle of addiction, violence, and shame: A dance/movement therapy group approach in a jail addictions program. Journal of Groups in Addiction $\mathcal{F}$ Recovery, 3(1-2), 5-22. doi:10.1080/15560350802157346

Miner, J. (2002). The children are free : Reexamining the biblical evidence on same-sex relationships. Indianapolis, Indiana: Jesus Metropolitan Community Church.

Mitchell, K. J., Ybarra, M. L., Korchmaros, J. D., \& Kosciw, J. G. (2013). Accessing sexual health information online: use, motivations and consequences for youth with different sexual orientations. Health Education Research, 29(1), 147-157. doi:10.1093/her/cyt071 
Morrison, A., \& Ferris, J. (2002).

Contemporary Family Therapy, 24(1), 161-180. doi:10.1023/a:1014333924555

Moses, M. (2020). Christianity and queerness. Eidos, 9(1), 70-73. Retrieved from http://xaviers.edu.in/ ojs3/index.php/eidos/article/view/101

Murray, C., Pope, A., \& Willis, B. (2017). Sexuality counseling : theory, research, and practice. Thousand Oaks, CA: SAGE.

Murray, K. M., Ciarrocchi, J. W., \& Murray-Swank, N. A. (2007). Spirituality, religiosity, shame and guilt as predictors of sexual attitudes and experiences. Journal of Psychology and Theology, 35(3), 222-234. doi:10.1177/009164710703500305

Owens, E. W., Behun, R. J., Manning, J. C., \& Reid, R. C. (2012). The impact of internet pornography on adolescents: A review of the research. Sexual Addiction E Compulsivity, 19(1-2), 99-122. doi:10.1080/10720162.2012.660431

Paudel, A., \& Dong, Q. (2017). The discrimination of women in buddhism: An ethical analysis. OALib, 04(04), 1-18. doi:10.4236/oalib.1103578

Perry, S. L. (2015). Pornography consumption as a threat to religious socialization. Sociology of Religion, srv043. doi:10.1093/socrel/srv043

Pulverman, C. S., Kilimnik, C. D., \& Meston, C. M. (2018). The impact of childhood sexual abuse on women's sexual health: A comprehensive review. Sexual Medicine Reviews, 6(2), 188-200. doi:10.1016/j.sxmr.2017.12.002

Pulverman, C. S., \& Meston, C. M. (2020). Sexual dysfunction in women with a history of childhood sexual abuse: The role of sexual shame. Psychological Trauma: Theory, Research, Practice, and Policy, 12(3), 291-299. doi:10.1037/tra0000506

Ringrose, J., \& Harvey, L. (2015). Boobs, backoff, six packs and bits: Mediated body parts, gendered reward, and sexual shame in teens' sexting images. Continuиm, 29(2), 205-217. doi:10.1080/10304312.2015.1022952

Rizvi, S. L. (2009). Development and preliminary validation of a new measure to assess shame: The shame inventory. Journal of Psychopathology and Behavioral Assessment, 32(3), 438-447. doi:10.1007/s10862-0099172-y

Rubinsky, V., \& Cooke-Jackson, A. (2016). "where is the love?" expanding and theorizing with LGBTQ memorable messages of sex and sexuality. Health Communication, 32(12), 1472-1480. doi:10.1080/10410236.2016.1230809

Rubinsky, V., \& Cooke-Jackson, A. (2017). "tell me something other than to use a condom and sex is scary": Memorable messages women and gender minorities wish for and recall about sexual health. Women's Studies in Communication, 40(4), 379-400. doi:10.1080/07491409.2017.1368761

Russell, E. B. (2012). Sexual health attitudes, knowledge, and clinical behaviors. The Family Journal, 20(1), 94101. doi:10.1177/1066480711430196

Sanchez, D. T., \& Kiefer, A. K. (2007). Body concerns in and out of the bedroom: Implications for sexual pleasure and problems. Archives of Sexual Behavior, 36(6), 808-820. doi:10.1007/s10508-007-9205-0

Santelli, J. S., Kantor, L. M., Grilo, S. A., Speizer, I. S., Lindberg, L. D., Heitel, J., ... Ott, M. A. (2017). Abstinence-only-until-marriage: An updated review of u.s. policies and programs and their impact. Journal of Adolescent Health, 61(3), 273-280. doi:10.1016/j.jadohealth.2017.05.031

Sellers, T. (2017). Sex, God, and the conservative church: Balancing faith and sexual shame. New York, NY: Routledge.

Shadbolt, C. (2009). Sexuality and shame. Transactional Analysis Journal, 39(2), 163-172. doi:10.1177/036215370903900210

Sherry, A., Adelman, A., Whilde, M. R., \& Quick, D. (2010). Competing selves: Negotiating the intersection of spiritual and sexual identities. Professional Psychology: Research and Practice, 41(2), 112-119. doi: $10.1037 / \mathrm{a} 0017471$

Southern, S., \& Cade, R. (2011). Sexuality counseling: A professional specialization comes of age. The Family Journal, 19(3), 246-262. doi: $10.1177 / 1066480711408028$

Tangney, J., \& Dearing, R. (2002). Shame and guilt. New York: Guilford Press.

Thomas, J. N., Alper, B. A., \& Gleason, S. A. (2017). Anti-pornography narratives as self-fulfilling prophecies: Religious variation in the effect that pornography viewing has on the marital happiness of husbands. Review of Religious Research, 59(4), 471-497. doi:10.1007/s13644-017-0301-x

Vidal, M. E., \& Petrak, J. (2007). Shame and adult sexual assault: a study with a group of female survivors recruited from an east london population. Sexual and Relationship Therapy, 22(2), 159-171. doi:10.1080/14681990600784143

Willie, T. C., Overstreet, N. M., Peasant, C., Kershaw, T., Sikkema, K. J., \& Hansen, N. B. (2016). Anxiety and depressive symptoms among people living with HIV and childhood sexual abuse: The role of shame and posttraumatic growth. AIDS and Behavior, 20(8), 1609-1620. doi:10.1007/s10461-016-1298-9

Wilson, M. R. (2019). Too taboo?: Preliminary explorations of counselor experiences of client sexuality. Journal of Counseling Sexology E Sexual Well- 
ness: Research, Practice, and Education, 1(1), 60-68. doi:10.34296/01011010

World Health Organization. (2002). Gender and human rights: Sexual health. Author. Retrieved from WWW . who . int/reproductive/health/topics/ gender_rights/sexual_health/en/

World Health Organization. (2011). Sexual and reproductive health: Core competencies in primary care. Author. Retrieved from https://WwW.who.int/ reproductivehealth/publications/ health_systems/9789241501002/en/ 